\title{
EM BUSCA DOS ANTIGOS BANCOS DO "PÁTIO DAS ARCADAS" DA ACADEMIA DE DIREITO DE SÃO PAULO ${ }^{1}$
}

\author{
IN SEARCH OF THE OLD BENCHES FROM THE “ARCADES COURTYARD” OF THE SÃO PAULO \\ LAW SCHOOL
}

\author{
Eduardo Cesar Silveira Marchi ${ }^{2}$ \\ Diego Amorim Grola ${ }^{3}$
}

\begin{abstract}
Resumo:
Reconstituição histórica, com base em fontes iconográficas, da aparência e dos detalhes arquitetônicos dos antigos bancos que ornavam o "Pátio das Arcadas" da Academia de Direito do Largo de São Francisco até o final dos anos 30 do século XX, e tentativa de localização de exemplar sobrevivente deste tipo de mobiliário, para a confecção de réplicas.

Palavras-chave: Patrimônio histórico. Mobiliário. Cultura material. "Pátio das Arcadas".

Abstract:

Historical reconstitution, through iconographic sources, of the appearance and architectural details of the old benches the existed in the "Arcades Courtyard" of the São Paulo Law School of the "Largo de São Francisco", until the end of the Thirties of century XX, and attempt to locate of surviving unit of this type of furniture, to make reproductions.
\end{abstract}

Keywords: Historic patrimonial. Mobiliary. Material culture. "Arcades Courtyard".

$\mathrm{Na}$ iconografia - antigas pinturas e fotografias - do histórico "Pátio das Arcadas" da Academia de Direito do Largo de São Francisco, especialmente no período entre o final do século XIX e o início dos anos trinta do século passado, aparecem, ornando o famoso claustro, alguns bancos de um mesmo tipo.

Trata-se de um móvel do estilo "banco de jardim", com assento e encosto compostos de ripas de madeira fixadas lado a lado, e montadas em duas paralelas estruturas

\footnotetext{
Este artigo é uma adaptação e complementação de um texto de mesmo título, exposto em painel no "hall" de entrada da FDUSP entre abril e julho de 2006, bem como no Vox Ianorum: Boletim Informativo da Faculdade de Direito da USP, ano 2, n. 1, março/maio 2006, p. 8 . O trabalho apresentado naquela ocasião fazia parte das atividades desenvolvidas no âmbito do Projeto de Resgate Histórico das Tradições e dos Principais Acontecimentos Acadêmicos da Faculdade de Direito do Largo de São Francisco. Tal projeto, concebido e executado pelo Prof. Eduardo Cesar Silveira Vita Marchi, Diretor da Escola no período 2002-2006, teve como bolsista-colaborador o acadêmico Diego Amorim Grola, e contou com fundamental apoio da Pró-Reitoria de Pesquisa da USP, na gestão do Prof. Luiz Nunes D’Oliveira.

2 Professor Titular de Direito Romano da Faculdade de Direito da Universidade de São Paulo.

3 Acadêmico quartoanista de História da FFLCH da Universidade de São Paulo.
} 
de apoio (consistentes nos pés do assento e na base de apoio do encosto, em uma só peça), feitas em ferro fundido.

É o que se pode observar, por exemplo, em conhecido quadro de autoria de J. Wasth Rodrigues (figura 1), bem como em aquarela de A. H. V. Van Emelen (figura 2).

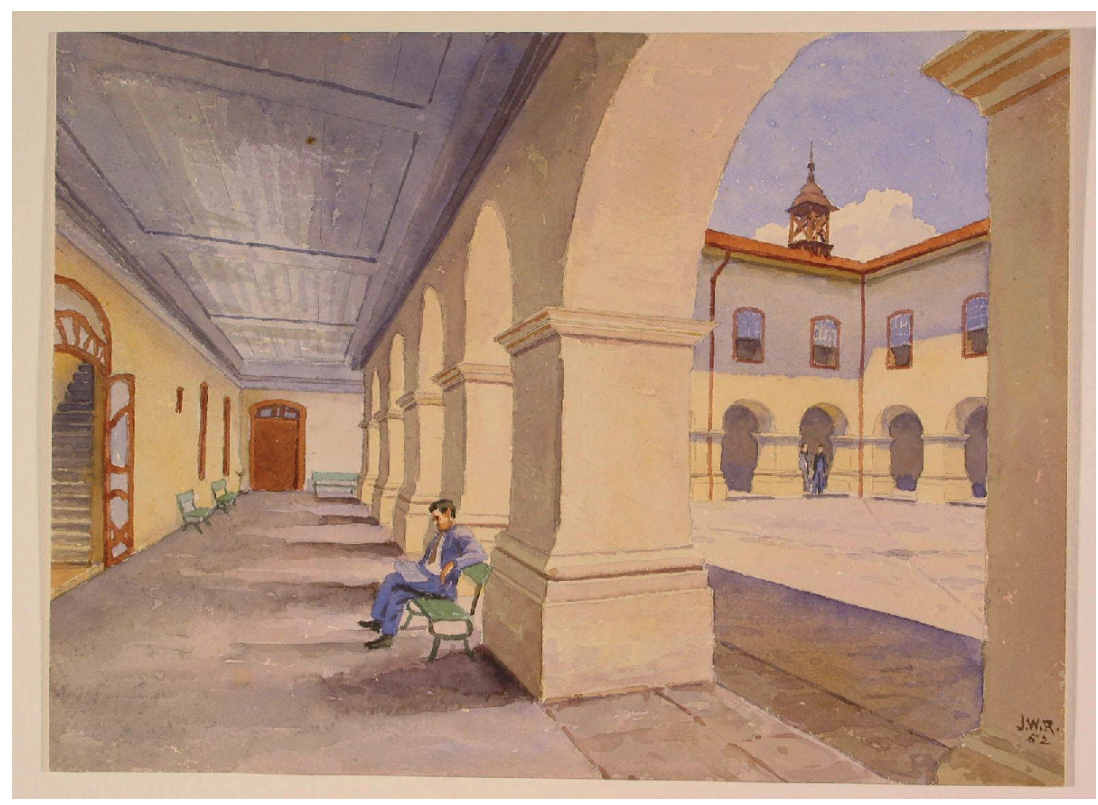

Figura 1. J. Wasth Rodrigues, Pátio da antiga Faculdade de Direito, aquarela, s.d. (mas depois de 1914), Acervo do Arquivo Histórico Municipal de São Paulo, disponível em: $<$ http://www.prodam.sp.gov.br/dhp/acervos/acaqua04.htm $>$. Acesso em: 04 dez. 2005.

Por razões artísticas, é quase certo que o artista não tenha sido fiel aos detalhes dos contornos dos pés de ferro fundido. Em todo caso, a estrutura geral do móvel se parece muitíssimo com a dos bancos posteriormente encontrados em outras fotografias e pinturas. 


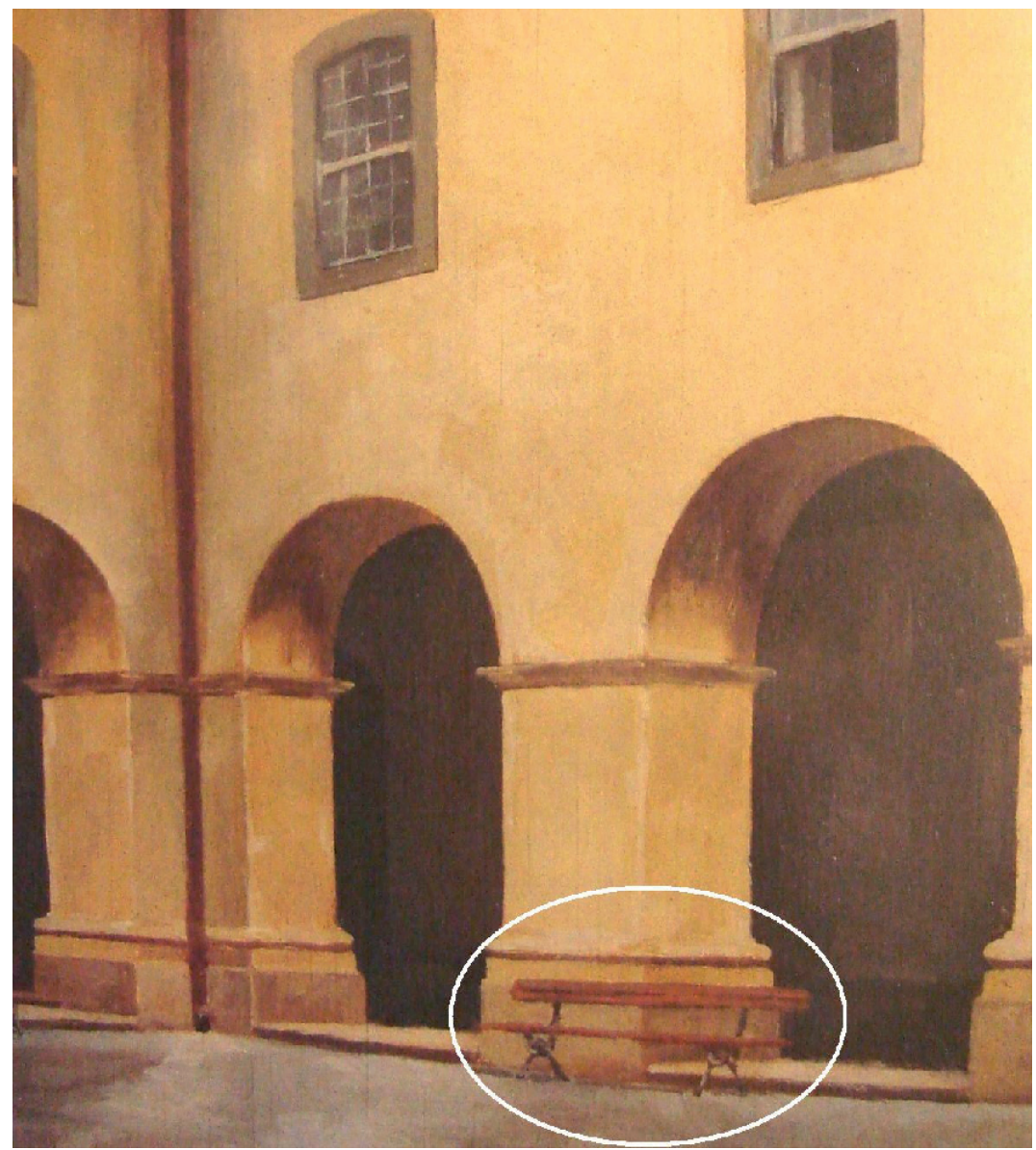

Figura 2. A. H. Van Emelen, Academia de Direito. óleo sobre madeira, s.d. (mas por volta de 1920), Acervo da Pinacoteca do Estado de São Paulo. In: BARBUY, Heloiza; MARTINS, Ana Luiza. Arcadas: história da Faculdade de Direito do Largo de São Francisco, 1827-1997. São Paulo: Alternativa, 1998. p. 18.

No caso de A. H. V. Emelen a preocupação realística manifesta-se mais claramente, representando os bancos com maior fidelidade. De qualquer modo, a proporção do móvel em relação aos outros elementos da tela impediu que fossem representados os exatos contornos do banco em todos os seus detalhes.

Tal mobiliário, por outro lado, parece não ter sido utilizado apenas no "Pátio das Arcadas". É quase certo que esta espécie de banco também tenha servido como assento de alunos das antigas salas de aula do velho edifício da Academia. 
Recorde-se, neste sentido, afirmação de J. J. Cardozo de Mello Neto, Diretor da Escola entre 1941 e 1943, ao fazer, aparentemente, referência a tais bancos, enquanto traça a biografia do também antigo Diretor A. Dino C. Bueno (1908-1912): “Ele moderniza pela primeira vez o mobiliário que, em nosso tempo, consistia em bancos de madeira para cinco estudantes". ${ }^{4}$

A alusão a estes bancos das antigas salas de aula da Academia é também feita em outra passagem, ao se relatarem as obras da gestão daquele mesmo Diretor A. Dino C. Bueno: "[Ele] substituiu os célebres bancos acadêmicos por mais confortáveis poltronas". 5

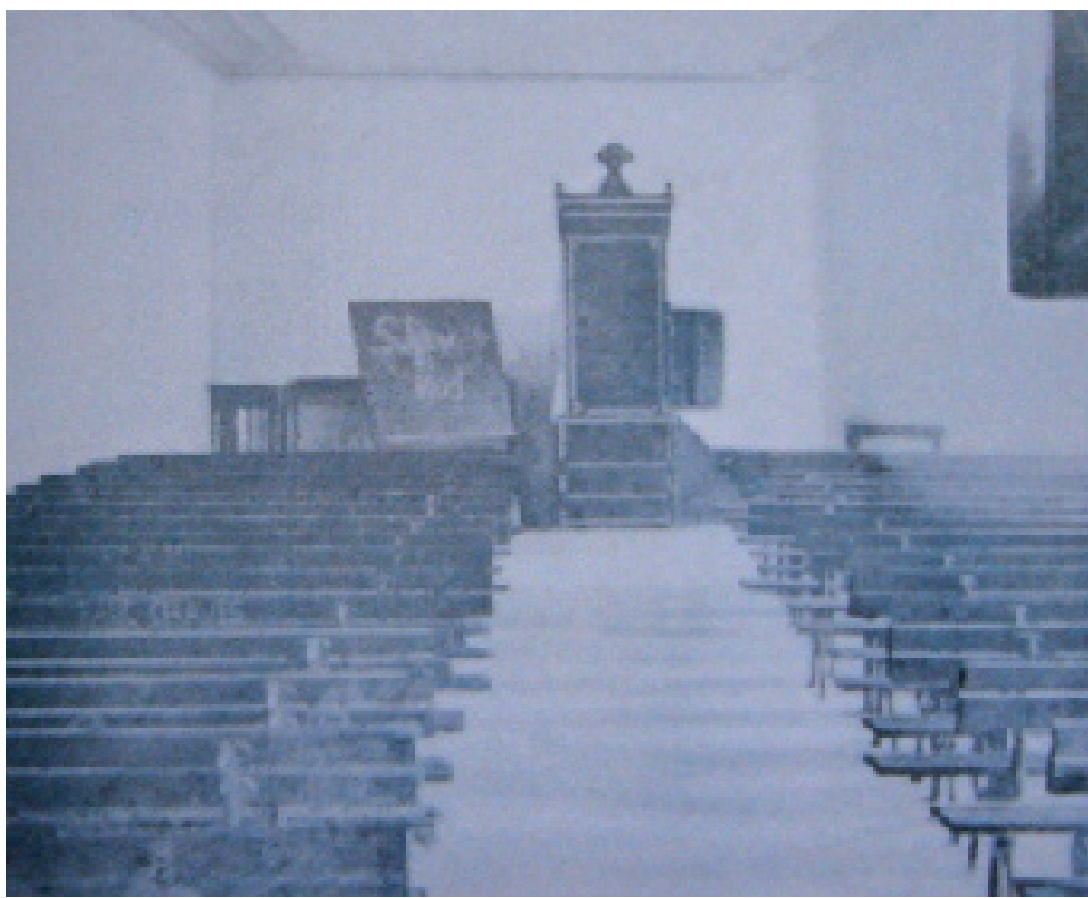

Figura 3. Sala número 2, da Faculdade de Direito de São Paulo, Fotografia, 1905, in J. Martin; R. Pestana, São Paulo Antigo e São Paulo Moderno, São Paulo, Vannorden, 1905 (ora In: BARBUY, Heloiza; MARTINS, Ana Luiza. Arcadas: história da Faculdade de Direito do Largo de São Francisco, 1827-1997. São Paulo: Alternativa, 1998. p. 122).

4 Mello NeTO, J. J. Cardozo de. Dino Bueno. Revista da Faculdade de Direito de São Paulo, São Paulo, v. 58, p. 312-318, 1963. p. 316.

5 Antonio Dino da Costa Bueno. Revista da Faculdade de Direito de São Paulo, São Paulo, v. 27, 137-148, 1931. p. 147. Não se indica, neste relato biográfico, o seu autor. Por conseqüência, devemos oficialmente atribuí-lo à Comissão de Redação da Revista, à época composta pelos Profs. J. Alcântara Machado D'Oliveira (Presidente), J. J. Cardozo de Mello Neto, Waldemar M. Ferreira e A. Sampaio Doria. 
Esta fotografia é um indício de que os bancos usados nas salas de aula até a primeira década do século XX podem ter sido do mesmo tipo daqueles que se encontravam no "Pátio das Arcadas".

Esta suposição - de que os bancos do "Pátio" e aqueles das salas de aula fossem os mesmos - encontraria, enfim, confirmação em uma velha fotografia da antiga sala de aula n. 2 (figura 3) do velho edifício da Academia.

Nela podem ser vistos os referidos bancos, os quais, aliás, certamente pode-se visualizar e imaginar - geravam, como já acima atestado, bastante desconforto aos estudantes.

No tocante à iconografia deste mobiliário do "Pátio das Arcadas" (e, muito possivelmente, como se viu, também dos assentos das salas de aula) bastante relevantes são ainda outras três imagens.

Na primeira, reproduzida na já clássica obra de H. Barbuy e A. Martins ${ }^{6}$ sobre a história da Faculdade, aparecem alguns bacharéis recém-formados da turma de 1924 que, pousando para fotografia no Pátio, sentam-se nos antigos bancos (figuras 4 e 5).

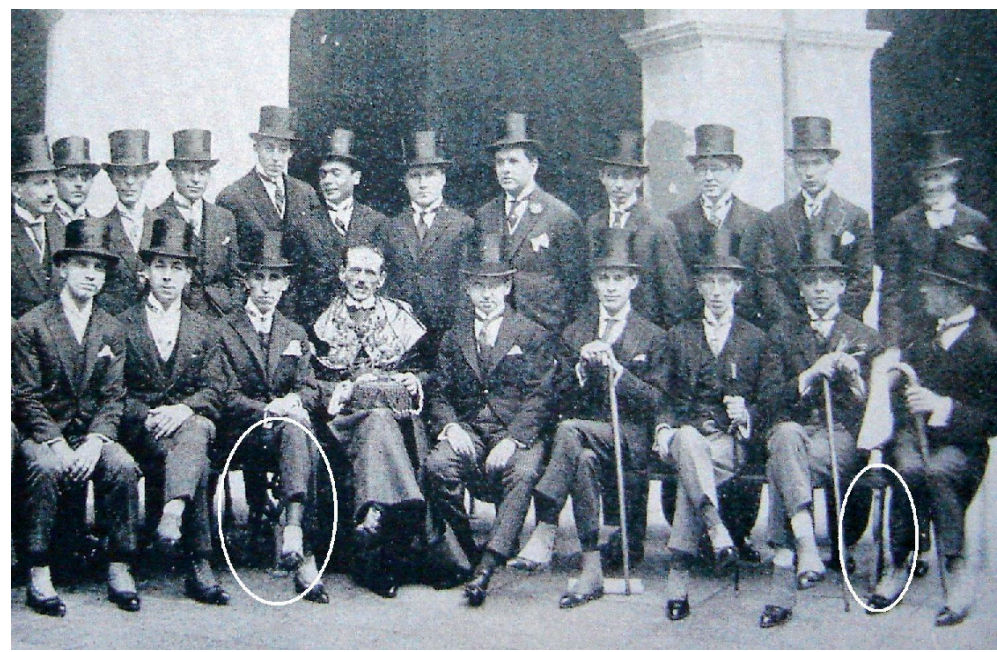

Figura 4. Bacharéis formados pela Faculdade de Direito de São Paulo com o paraninfo, Prof. Francisco Morato, fotografia, 1924, in Illustração Brasileira 54 (1925), Rio de Janeiro (ora In: BARBUY, Heloiza; MARTINS, Ana Luiza. Arcadas: história da Faculdade de Direito do Largo de São Francisco, 1827-1997. São Paulo: Alternativa, 1998. p. 143).

É possível observar nas áreas assinaladas alguns detalhes da estrutura dos pés em ferro batido dos antigos bancos.

6 BARBUY, Heloiza; MARTINS, Ana Luiza. Arcadas: história da Faculdade de Direito do Largo de São Francisco, 1827-1997. São Paulo: Alternativa, 1998. 


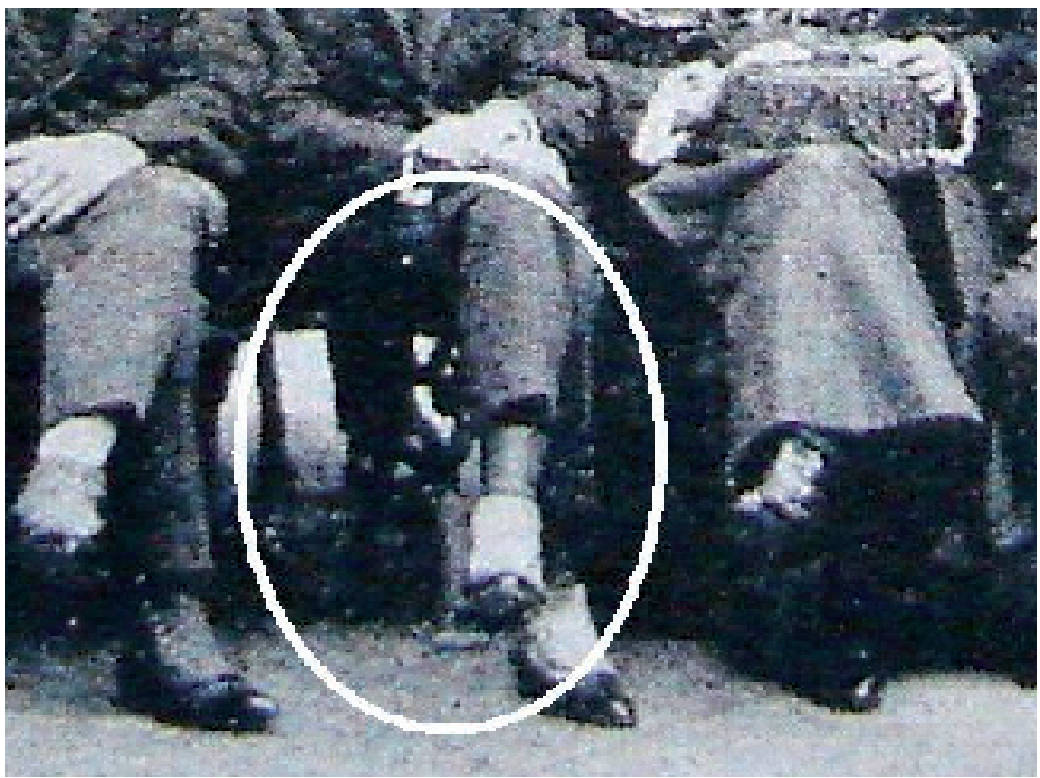

Figura 5 - (Detalhe da Figura 4)

Outra imagem, com representação semelhante, foi também encontrada no acervo fotográfico do Arquivo da Faculdade (figura 6).

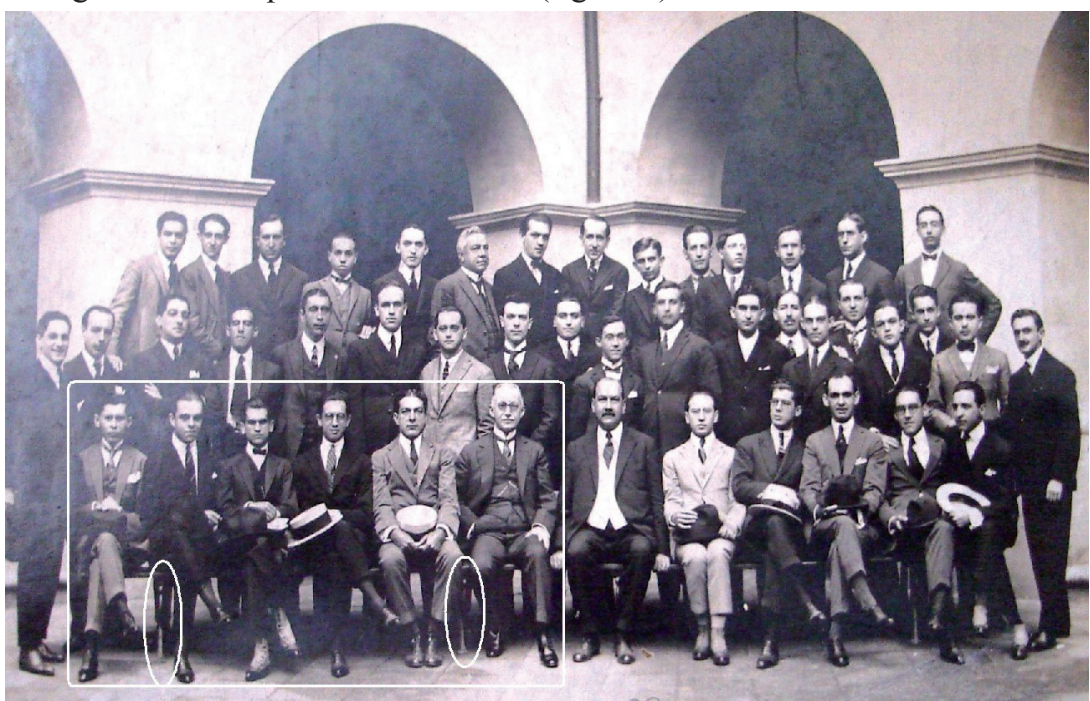

Figura 6. Formandos de 1923, fotografia, 1923, Acervo do Arquivo da Faculdade de Direito da USP.

Pode-se, nesta fotografia, perceber e calcular a capacidade aproximada dos bancos: cinco pessoas (ou até seis, em posição comprimida). 
Por fim, uma terceira fotografia, integrante da coleção da Biblioteca da Faculdade de Arquitetura e Urbanismo (FAU) da USP, mostrou-se particularmente interessante, por possibilitar um reconhecimento mais nítido da aparência dos bancos procurados, em especial dos contornos dos pés em ferro fundido.

No canto esquerdo da foto aparece a parte lateral do banco. Observando-se de maneira mais atenta, pode-se notar a identidade entre a peça contida nesta imagem e aquelas presentes nas reproduções anteriores (figuras 7 e 8).

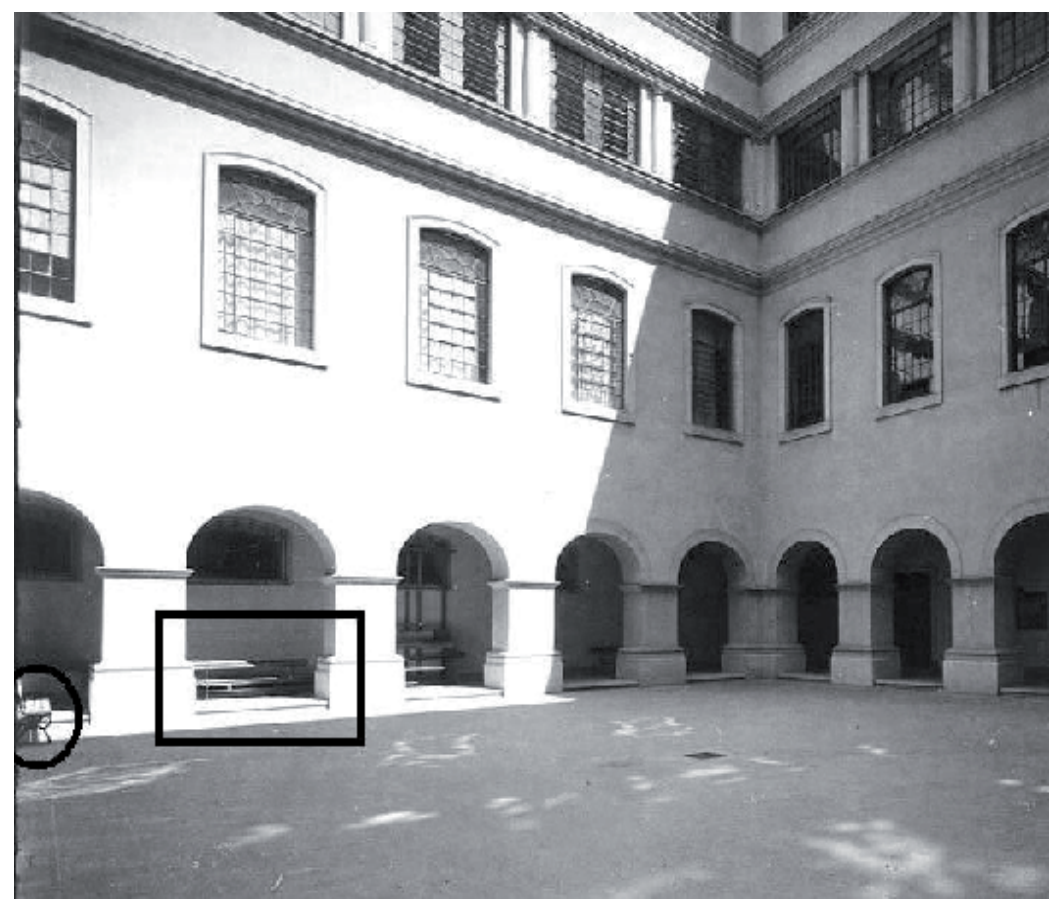

Figura 7. "Pátio das Arcadas" da Faculdade de Direito da USP, fotografia, s.d. (mas por volta da década de 30), Coleção Escritório Severo \& Villares - Acervo da Biblioteca da FAU-USP.

No canto esquerdo, na área assinalada com um círculo, encontramos o nosso banco. Atente-se para o fato de que essa é uma fotografia do atual prédio da Faculdade, construído durante todo o decorres da década de 30. Portanto, os bancos devem ter sobrevivido na Faculdade até pelo menos o final da segunda metade da referida década.

Além do referido banco à esquerda, pode-se reparar outro dos bancos em visa frontal, sob a segunda Arcada da esquerda para a direita (área assinalada com um retângulo). 


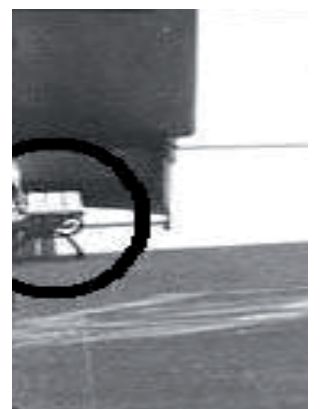

Figura 8 - (Detalhe da Figura 7)

As imagens até aqui reproduzidas, todas tomadas em espaços e locações tanto do antigo quanto do novo edifício da Faculdade, não permitiram, todavia, uma visualização adequada e mais exata dos detalhes arquitetônicos dos bancos do "Pátio das Arcadas".

Partindo-se da hipótese de que tais bancos pudessem também ter sido utilizados em outros locais ou praças públicas da antiga São Paulo (dada a provável falta de variedade de fabricantes em uma cidade ou região ainda em fase histórica inicial de industrialização), a procura por este antigo mobiliário foi então deslocada para a iconografia de outros logradouros externos à Academia.

Após intensas buscas, ${ }^{7}$ encontrou-se, junto aos antigos álbuns fotográficos do acervo da Biblioteca Municipal Mário de Andrade, uma tomada do Jardim da Luz em que é possível ter visão parcial de um banco provavelmente análogo àquele procurado (figuras 9 e 10).

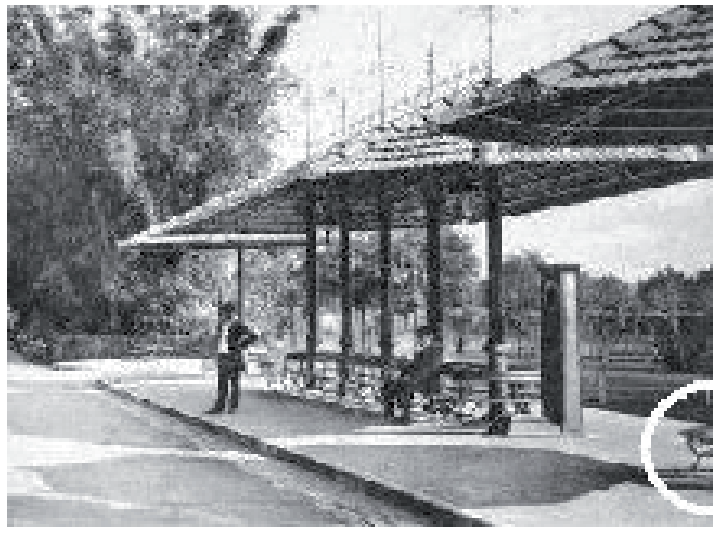

Figura 9. G. Gaensly, Jardim da Luz - São Paulo, fotografia, s.d. (mas por volta de 1901), Acervo da Biblioteca Municipal Mário de Andrade, disponível [on line] in

\footnotetext{
A pesquisa de imagens da antiga São Paulo teve lugar especialmente no Arquivo de Negativos do Município de São Paulo, nos álbuns fotográficos existentes na Biblioteca Municipal Mário de Andrade, bem como no material existente no Memorial do Ensino Municipal, no Centro de Referência em Educação Mário Covas e no Instituto de Estudos Brasileiros da USP.
} 
http://www.docpro.com.br [4-12-2005].

No canto direito é possível ter-se uma visão parcial de um banco semelhante (ou igual) ao do "Pátio das Arcadas".

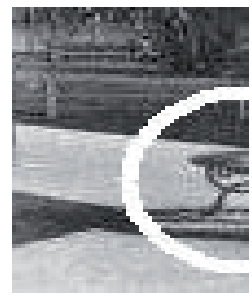

Figura 10 - (Detalhe da Figura 9)

A partir de tal imagem, chegou-se, por fim, à obra compilativa de J. Gerodetti e C. Cornejo, ${ }^{8}$ em que se reproduz um antigo cartão-postal do mesmo Jardim da Luz: nele pode-se claramente reconhecer e identificar um banco idêntico àqueles vistos nas fotografias e quadros com representações da Faculdade de Direito (figuras 11 e 12).

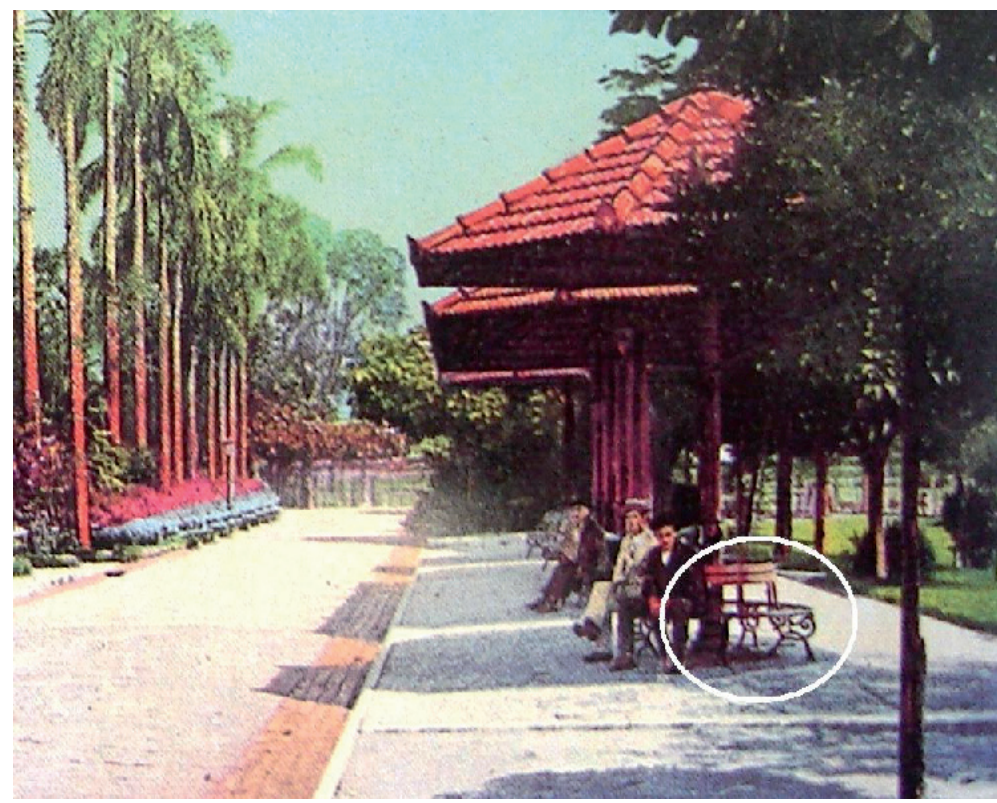

Figura 11. Jardim da Luz - São Paulo, cartão postal, s.d. (mas por volta de 1910). In: GERODETTI, J. E.; CORNEJO, C. Lembranças de São Paulo: a capital paulista nos cartões postais e álbuns de lembranças. 4. ed. São Paulo: Solaris, 2002. p. 164.

No canto direito, na área assinalada, encontra-se banco idêntico aos do "Pátio das Arcadas".

8 GERODETTI, J. E.; CORNEJO, C. Lembranças de São Paulo: a capital paulista nos cartões postais e álbuns de lembranças. 4. ed. São Paulo: Solaris, 2002. 


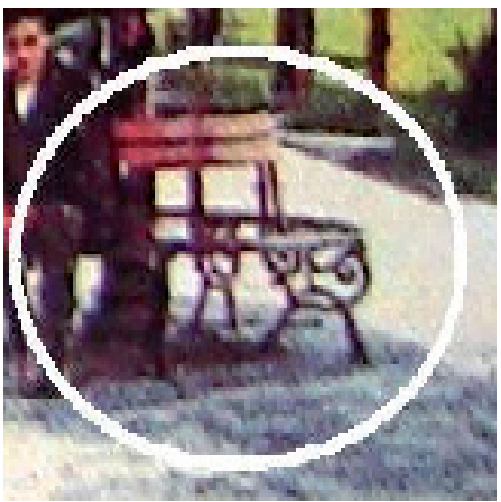

Figura 12 - (Detalhe da Figura 11)

Em outra obra com reprodução de retratos ainda do Jardim da Luz, ${ }^{9}$ também é possível visualizar-se, de longe, o mesmo móvel (figuras 13 e 14).

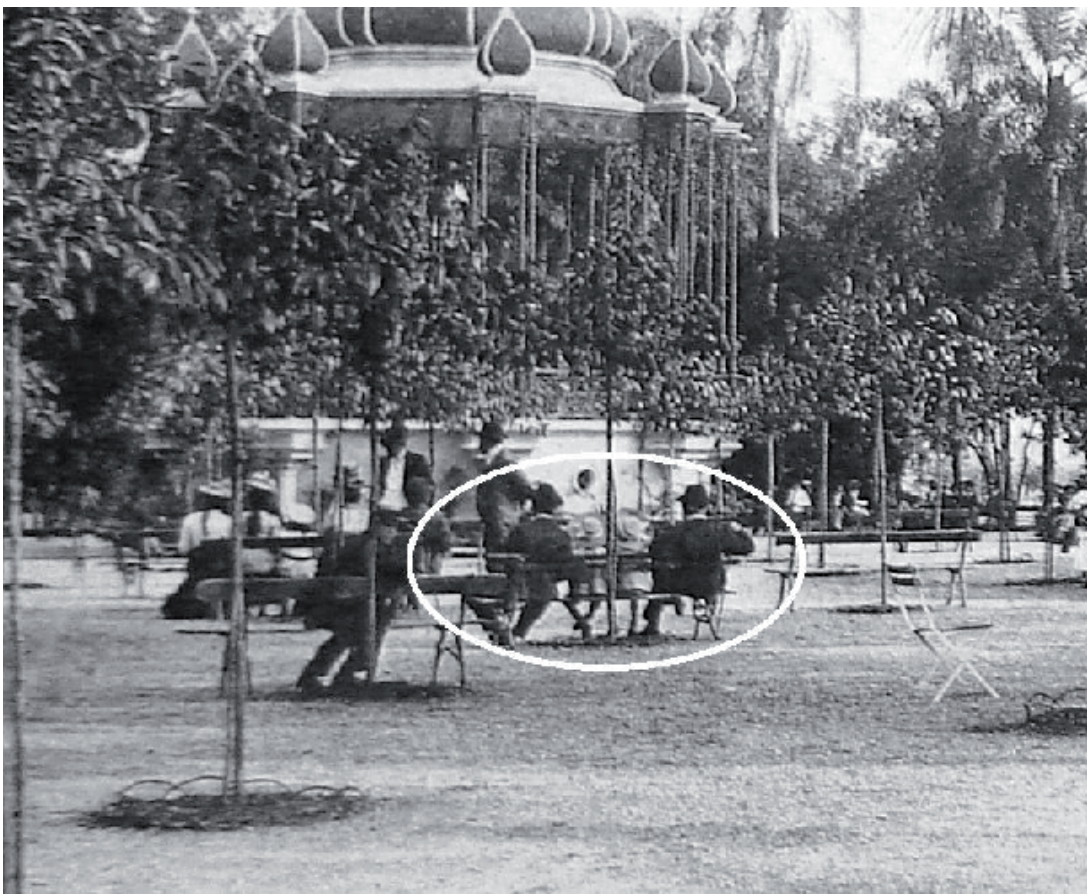

Figura 13. G. Gaensly, Jardim da Luz - São Paulo, fotografia, s.d. In: KOSSOY, B. São Paulo, 1900. São Paulo: Kosmo, 1988.

9 KOSSOY, B. São Paulo, 1900. São Paulo: Kosmo, 1988. 


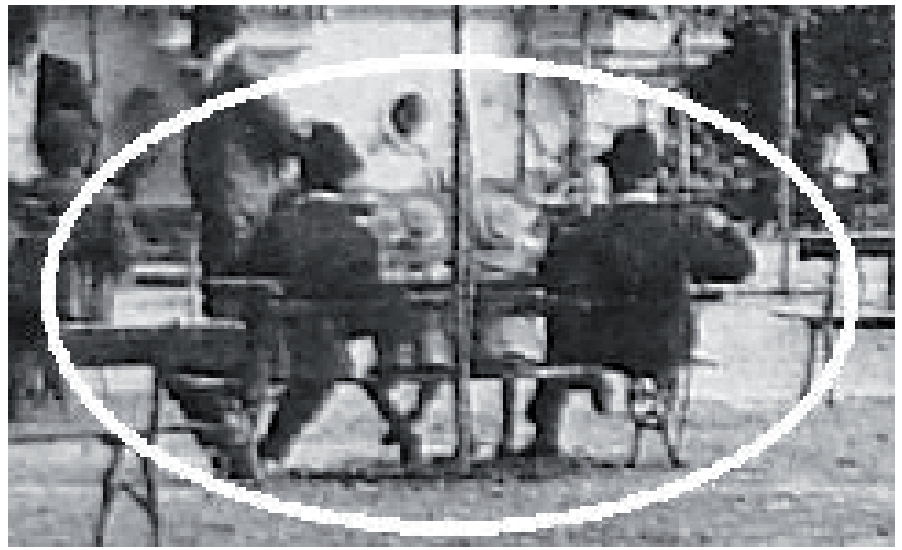

Figura 14

De todas as imagens pesquisadas, tanto na iconografia do velho Convento quanto da antiga São Paulo, a antepenúltima figura (12) foi a que possibilitou a melhor percepção dos exatos contornos dos pés de ferro fundido e dos demais detalhes do banco.

Com isto, foi então possível hipotizar, através de desenhos (figuras 15 e 16), ${ }^{10}$ a provável aparência original dos antigos bancos.

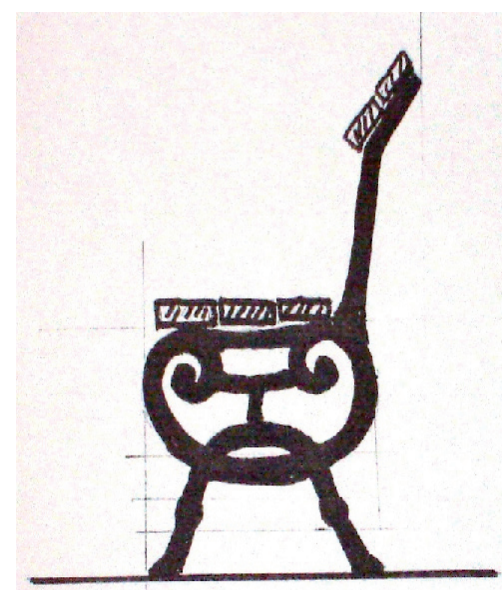

Figura 15. B. L. Toledo-E. C. Silveira Marchi; D. Amorim Grola, Antigo banco do Pátio das Arcadas, estudo preliminar sem escala.

A partir das imagens obtidas, tentou-se neste desenho e no seguinte reproduzir-se os detalhes arquitetônicos do banco procurado.

${ }^{10}$ Contou-se, neste ponto, com a preciosíssima colaboração do ilustre e renomado Prof. Benedito Lima de Toledo, Titular da Faculdade de Arquitetura e Urbanismo da Universidade de São Paulo. 


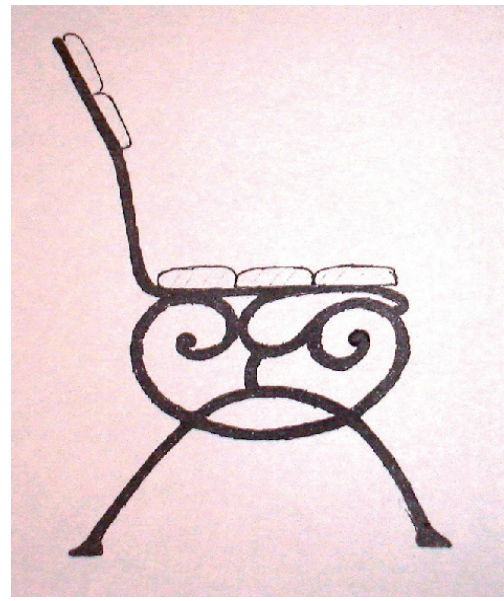

Figura 16. D. Amorim Grola, Antigo banco do Pátio das Arcadas, estudo sem escala.

Alcançada a reconstituição histórica das características e dos possíveis detalhes arquitetônicos (especialmente no que se refere aos contornos dos pés de ferro) deste antigo mobiliário do Claustro, pensou-se, como passo seguinte, na possibilidade de confecção de réplicas fiéis dos antigos bancos.

Desta maneira, o histórico "Pátio das Arcadas" poderia retomar o mesmo aspecto visual que apresentou durante algumas décadas de sua gloriosa história.

Todavia, a desejada fabricação de réplicas sem dispor de um modelo original apresentou sérias dificuldades: altos custos para a preparação, primeiro, de um projeto inicial, e, em seguida, de um protótipo em tamanho natural, especialmente da estrutura de apoio (com os pés e as bases do encosto em uma só peça), para, só depois, ao final, ser confeccionado um molde para fundição.

Os óbices decorreram também do fato, como se viu, de que as pinturas e fotografias localizadas não permitiam uma visualização absolutamente perfeita dos bancos, necessária para o desenho arquitetônico do projeto inicial.

Assim, o ideal, em todos os aspectos, para o trabalho de confecção de cópias, seria a eventual localização de algum exemplar original sobrevivente daqueles antigos bancos das Arcadas, de maneira a servir de molde para a fundição da estrutura em ferro fundido.

A busca por um modelo supérstite de tais bancos teve então início.

Partiu-se do pressuposto de que alguns deles pudessem ter sido preservados em museus, antigas escolas, igrejas, estações de trem, praças e outros logradouros públicos de São Paulo e região. 
Nessa procura ocorreram inúmeras visitas, como, por exemplo, ao Museu de Arte Sacra, Memorial do Imigrante no Brás, Jardim da Luz, Convento e Igrejas das Ordens Primeira e Terceira de São Francisco (ao lado da Escola), Museu Paulista da USP (Museu do Ipiranga), Museu da Casa Brasileira e Museu dos Transportes Públicos. ${ }^{11}$

Nada foi encontrado. ${ }^{12}$

Os raríssimos e excepcionais exemplares originais de antigos bancos localizados (como uma vetusta peça ainda em uso no Memorial do Imigrante) eram de modelo diverso daqueles que existiam nas Arcadas.

Foi, então, realizada uma mostra, no "hall" de entrada da Escola, com a exposição pública, em forma de painéis, dos resultados até então alcançados na pesquisa histórica.

Na parte final do texto da exposição, incitou-se, em tais buscas, a participação de todos - especialmente dos professores, estudantes e funcionários da Faculdade.

Passadas algumas semanas, em uma extraordinária coincidência, foram quase simultaneamente localizados, por acaso e em diferentes locais da Capital, dois exemplares originais sobreviventes, idênticos àqueles do "Pátio das Arcadas": o primeiro, em mal estado de conservação, na antiga Estação de Trem Vila Clarisse, ${ }^{13}$ em Pirituba, e o segundo (na verdade duas peças), bem conservado, na entrada de um prédio residencial da Rua Fradique Coutinho, no bairro de Pinheiros. ${ }^{14}$

Cedido em comodato à Escola o segundo exemplar, ${ }^{15}$ foi então possível, contratada empresa especializada, extrair-se o molde ${ }^{16}$ de um dos seus pés, vale dizer, da

\footnotetext{
${ }^{11}$ As quatro primeiras a cargo do primeiro co-autor; as três últimas, do segundo.

${ }^{12}$ Não se deixou também de consultar empresas especializadas com o objetivo de saber se esses bancos ainda eram fabricados. Também sem sucesso.

${ }^{13}$ Tal estação, construída em 1955 pela antiga Estrada de Ferro Santos-Jundiaí, sucessora da histórica "São Paulo Railway", encontra-se, atualmente, sob responsabilidade da Concessionária MRS.

${ }^{14} \mathrm{O}$ primeiro exemplar foi localizado pelo funcionário Franklin de França, da Seção de Informática da Faculdade, e os outros dois foram encontrados casualmente - em outra surpreendente e notável coincidência - pelo próprio bolsista-colaborador do "Projeto Resgate Histórico" referido, Diego Amorim Grola, em visita ao edifício da nova moradia de um parente.

${ }^{15}$ Os dois bancos supérstites encontrados no edifício de Pinheiros, pelas informações orais colhidas, parece terem vindo da chamada Casa das Rosas, construção histórica tombada situada na Avenida Paulista (construída em 1935 pelo famoso arquiteto e construtor F. P. Ramos de Azevedo, para servir de moradia à uma de suas filhas), quando do seu restauro pela construtora do arquiteto Júlio Neves, na segunda metade dos anos 80 .

${ }^{16}$ Solicitou-se à empresa especializada não-só a fabricação das réplicas mas também a entrega para a Escola do molde de fundição confeccionado (molde este em seguida depositado no Museu da Faculdade), de maneira a poder servir, no futuro, para a fabricação - querendo-se - de mais cópias de tais bancos, não-só para a Academia, como também para outros logradouros históricos da cidade de São Paulo, dos quais eles, uma vez, fizeram parte.
} 
estrutura em ferro da base de apoio e do encosto (consistente em uma só peça, como já se disse).

Em seguida, calculou-se, com base na iconografia levantada, a largura original aproximada dos bancos, para o corte das pranchas de madeira do assento e do encosto.

Foram, então, finalmente, fabricadas quinze réplicas fiéis do histórico móvel ${ }^{17}$ (figuras 17 e 18).

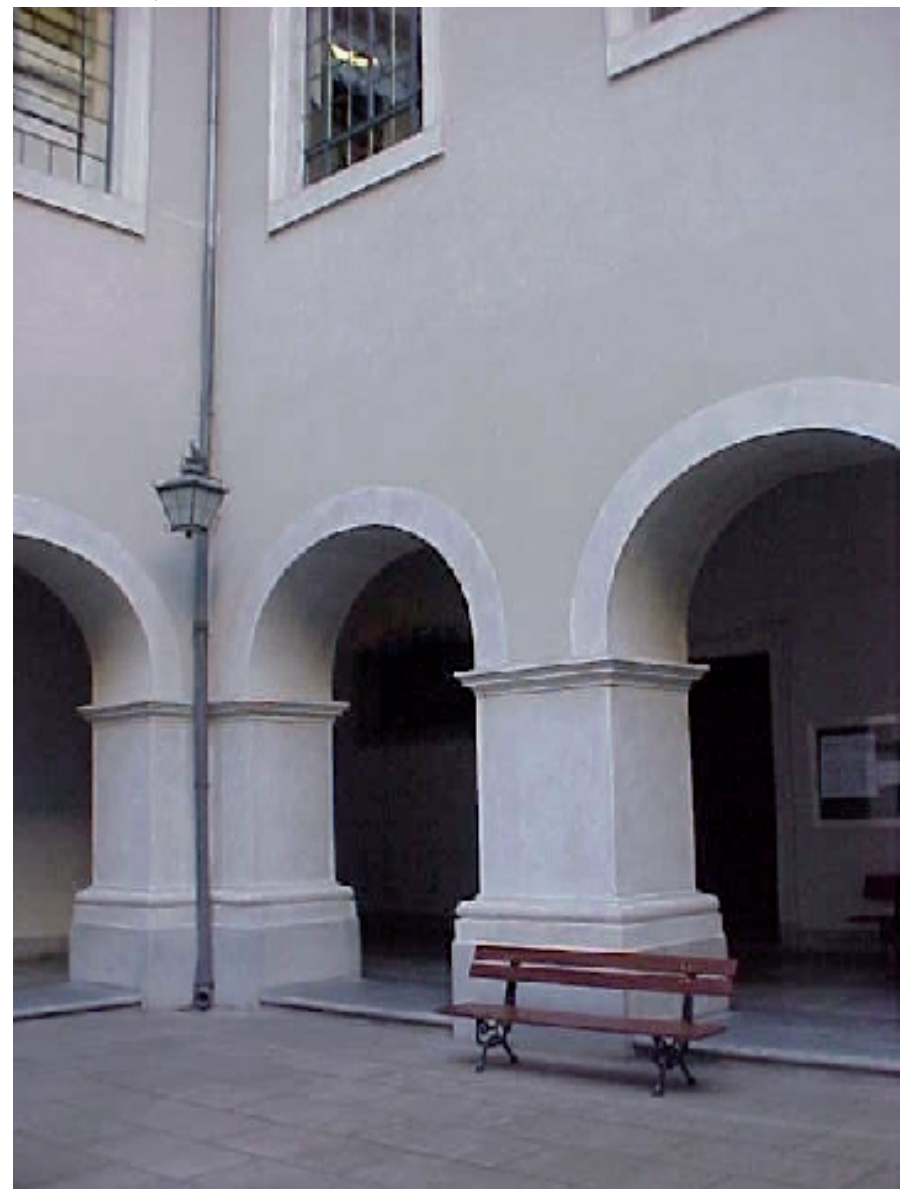

Figura 17. Uma das novas réplicas recolocadas no Pátio.

17 O número corresponde à quantidade de Arcadas dos três braços do Pátio não destinados à circulação, isto é, com exclusão daquele correspondente ao "hall" dos elevadores e da escada de acesso aos andares superiores do edifício. 


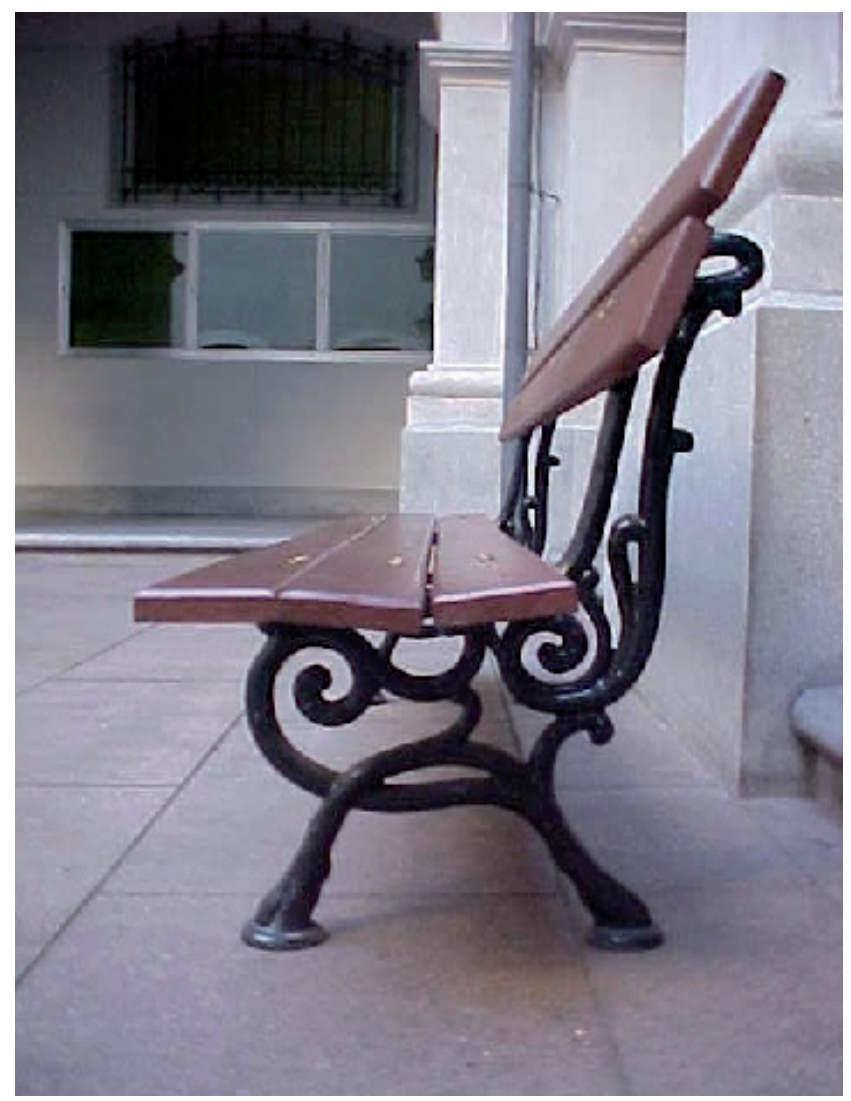

Figura 17. Detalhe de uma das novas réplicas.

Em 8 de agosto de 2006, no âmbito das festividades da Semana de comemoração do $179^{\circ}$ Aniversário de Fundação da Academia de Direito de São Paulo, os antigos bancos enfim retomaram seu lugar no histórico "Pátio das Arcadas". ${ }^{18}$

18 Decorrido quase um ano da reposição dos antigos bancos, verificou-se interessante fenômeno. As (poucas) bancadas de madeira maciça que se encontravam anteriormente no Pátio, por serem grandes (com capacidade para sete ou oito pessoas) e bastante pesadas, dificultavam o seu deslocamento por parte dos alunos. Com a reintrodução das réplicas dos antigos móveis, relativamente leves (apesar dos pés de ferro), passou-se a verificar uma intensa utilização e deslocamento dos novos velhos bancos por parte dos estudantes (gerando também, aliás, uma maior interação entre eles naquele espaço), muitas vezes com a sua colocação no meio do Pátio: como resultado, é comum hoje, diariamente, encontrarem-se os bancos posicionados aleatoriamente e de maneira desorganizada, ora na parte interna de algumas das Arcadas ora ao relento.

Tal novo visual do Pátio, com os bancos assim desordenadamente posicionados, corresponde exatamente ao relato do antigo aluno Dr. Francisco de Assumpção Ladeira, da turma de 1933, um dos últimos estudantes ainda vivos daquela época, em depoimento colhido no dia 14 de julho de 2006, no âmbito do Programa de História Oral da Faculdade de Direito do Largo de São Francisco (com o material ainda não-publicado), parte do Projeto de Resgate Histórico já mencionado (cf. nota 1 supra). 